\title{
HUBUNGAN PENGETAHUAN TENTANG MENARCHE DENGAN TINGKAT KECEMASAN REMAJA PUTRI AWAL (Studi Di Madrasah Ibtidaiyah Darul Ulum Madurejo)
}

\author{
Achmad Yamani Risa Putra ${ }^{1}$ Christina T Setiawan ${ }^{2}$ Rahaju Wiludjeng ${ }^{3}$ \\ ${ }^{1}$ STIKes Insan Cendekia Medika ${ }^{23}$ STIKes Borneo Cendekia Medika Pangkalan \\ Bun \\ 1email : yamanirisa@gmail.com, 2email : csetiawan.366@gmail.com, 3email : \\ ira.wiludjeng@gmail.com
}

\begin{abstract}
ABSTRAK
Pendahuluan: Menstruasi pertama kali atau dikenal dengan istilah menarche akan dialami setiap wanita saat masa pubertas. Mereka yang pertama kali mengalami akan takut dan cemas mengenai keadaan yang dialaminya. Informasi mengenai menarche diharapkan dapat mengurangi tingkat kecemasan pada remaja. Kecemasan merupakan respon seseorang mengenai suatu hal yang dirasa mengkhawatirkan. Mengetahui apakah ada hubungan pengetahuan tentang menarche dengan tingkat kecemasan remaja putri awal di Madrasah Ibtidaiyah Darul Ulum Madurejo merupakan tujuan dilakukannya penelitian ini. Metode penelitian: Desain penelitian deskriptif kuantitatif ini memiliki pendekatan cross sectional. Penelitian dilakukan pada bulan April hingga Juli 2017 dengan jumlah populasi 16 remaja putri, teknik sampling yang dipilih adalah tottal sampling sehingga jumlah sampel yang diperoleh 16 orang, data diambil menggunakan kuesioner DASS (Depression Anxiety Stress Scale). Dalam melakukan analisa data peneliti mengunakan uji chi-square. Hasil penelitian: Hasil penelitian ini didapatkan 10 siswi $(62,5 \%)$ memiliki pengetahuan kurang dan tingkat kecemasan berat, 5 siswi $(31,25 \%)$ memiliki pengetahuan cukup dan tingkat kecemasan sedang, dan 1 siswi $(6.25 \%)$ memiliki pengetahuan cukup dan tingkat kecemasan berat. Dengan $\mathrm{p}$ value $=0,009$ lebih kecil dari $\alpha$ value $=0,05$ maka dapat disimpulkan bahwa H0 ditolak dan H1 diterima. Kesimpulan: Jadi, dapat ditarik kesimpulan bahwa ada hubungan pengetahuan tentang menarche dengan tingkat kecemasan remaja putri awal di Madrasah Ibtidaiyah Darul Ulum Madurejo.
\end{abstract}

Kata Kunci : Menarche, Pengetahuan, Tingkat Kecemasan

\section{RELATIONSHIP KNOWLEDGE OF MENARCHE WITH ANXIETY LEVELS IN ADOLESCENT GIRLS \\ (Study In Madrasah Ibtidaiyah Darul Ulum Madurejo)}

\begin{abstract}
Introduction: The period of puberty in women is marked by the arrival of the first menstruation (menarche). If they already get the correct information about the coming of menstruation then they will not experience anxiety. Anxiety is a person's response to something that feels worrying. The purpose of this study is to determine whether there is a relationship knowledge about menarche with anxiety level early
\end{abstract}


adolescent girls in Madrasah Ibtidaiyah Darul Ulum Madurejo. Research method: This descriptive quantitative research design has cross sectional approach. The study was conducted from April to July 2017 with a population of 16 adolescent girls, the sampling technique chosen was tottal sampling so that the number of samples obtained 16 people, the data were taken using DASS (Depression Anxiety Stress Scale) questionnaire. In analyzing the data the researchers used chi-square test. Results: The results of this study showed that 10 students (62.5\%) had less knowledge and severe anxiety level, 5 students (31.25\%) had sufficient knowledge and moderate anxiety level, and 1 student (6.25\%) had sufficient knowledge and Severe anxiety level. With $p$ value $=0,009$ less than $\alpha$ value $=0,05$ it can be concluded that $\mathrm{HO}$ is rejected and $\mathrm{H} 1$ fails to be rejected. Conclusion: So, it can be deduced that there is a connection of knowledge about menarche with an early teenager's anxiety level in Madrasah Ibtidaiyah Darul Ulum Madurejo.

Keywords: Menarche, Knowledge, Anxiety Level

\section{PENDAHULUAN}

Perubahan seorang individu menuju fase dewasa pastinya akan melewati pada fase yang dinamakan sebagai remaja. Ketika seseorang memasuki usia 10-19 tahun maka bisa dikatakan dia sedang dalam fase remaja. (Ulfah, 2009 dalam Irmawati, 2013, 3). Pada fase ini individu akan banyak mengalami perubahan baik dari segi ukuran, banyaknya sel dalam tubuh, serta jaringan yang semakin banyak. Proses pertumbuhan merupakan proses berkesinambungan yang berasal dari gen atau keturunan, lingkungan sekitar, bio-psikososial mulai dari konsepsi sampai dewasa. Pertumbuhan linier dapat digunakan sebagai indikator yang mencerminkan kesehatan fisik dan mental. Seringkali gangguan pertumbuhan yang sebelumnya tidak terdeteksi akan muncul pada masa ini, serta masa remaja dikatakan juga sebagai kesempatan terakhir untuk melakukan intervensi sebelum terjadi penutupan lempeng epifisis. Pubertas dan kejadian percepatan pertumbuhan merupakan menifestasi dari berbagai pengaruh endokrin maupun non-endokrin.
Terjadinya kelainan pada proses ini akan berdampak sebagai gagal tumbuh, oleh karena betul sebagai seorang perawat harus mengerti betul pola pertumbuhan normal sebelum melakukan penelitian terhadap masalah pertumbuhan remaja.

Gangguan pertumbuhan dapat disebabkan oleh penyakit maupun bukan. Maka dari itu diperlukan analisa yang tepat dan suatu pemeriksaan yang akurat. Penanganan masalah kesehatan organ reproduksi remaja sudah mendapat perhatian serius dari pemerintahan. Perhatian yang intens haru diberikan pada remaja karena merekalah calon penerus bangsa. (Perkumpulan Keluarga Berencana Indonesia, 2002 dalam Irmawati, 2013, $3)$.

Jumlah remaja di Amerika Serikat sudah mencapai angka $15 \%$ dari total seluruh penduduknya. Untuk kawasan Asia yang jumlah populasinya merupakan $60 \%$ dari populasi global jumlah remajanya sendiri sudah memasuki angka sepertiganya (Maesaroh, 2010 didalam Yunika 2013, 2). Sebanyak 60.861 .350 jiwa 
merupakan jumlah remaja yang tercatat dan berada di kawasan indonesia atau dalam persentase sebanyak $30,2 \%$ dari keseluruhan populasi penduduk indonesia sendiri (Widyastuti, 2009 dalam Irmawati, 2013, 4).

Masa remaja akan sangat sering ditemui berbagai jenis perubahan baik dari segi fisik maupun psikologis. Banyak remaja yang merasa bingung akan hal yang dialami. Perhatian yang intens dan pemberian informasi mengenai perubahan yang terjadi pada diri mereka. Semakin banyak informasi yang diberikan diharapkan pengetahuan mereka juga akan bertambah. Pengetahuan yang dimiliki akan merubah sikap dan perilaku mereka mengenai kesehatan organ reproduksi. Kebanyakan remaja yang mengalami menstruasi pertama kali akan memberikan tanggapan yang kurang baik terhadap apa yang sedang dialaminya. Berk, (1993) dalam Irmawati, (2013, 7) remaja yang sedang mengalami haid pertama akan sering dijumpai keluhan baik secara fisik maupun psikologis dari segi fisik misalnya mereka terkadang merasakan nyeri dipinggang, rasa mual yang hebat, bahka ada yang mengeluhkan sakit pada kepala mereka. Dalam segi psikologis juga mengalami gangguan, biasanya wanita yang mengalami menstruasi mereka akan cenderung memiliki emosi yang kurang stabil, mereka bisa marah-marah mudah sekali tersinggung. Respon remaja tersebut dapat muncul karena kurangnya informasi mengenai perubahan yang terjadi pada mereka baik fisik maupun psikis. Mereka akan cenderung merasa cemas dan takut dalam menghadapi menarche.

$\begin{array}{lrr}\text { Dengan } & \text { dicetuskanya } & \text { Program } \\ \text { kesehatan } & \text { Reproduksi } & \text { Remaja }\end{array}$ diharapkan nantinya remaja akan berperilaku sehat dan bersikap baik pada kesehatan organ reproduksinya sehingga kedepannya mereka dapat terhindar dari berbagai masalah yang muncul pada sistem reproduksi mereka. (Badan Koordinasi Keluarga Berencana Nasional, 2002 dalam Irmawati, 2013, 5). Setelah memahami beberapa uraian diatas peneliti memutuskan untuk meneliti mengenai hubungan pengetahuan tentang menarche terhadap tingkat kecemasan remaja putri awal kelas 5-6 di Madrasah Ibtidaiyah Darul Ulum Madurejo, Pangkalan Bun, tahun 2017.

\section{METODE PENELITIAN}

Desain penelitian deskriptif kuantitatif ini memiliki pendekatan cross sectional. Penelitian dilakukan pada bulan April hingga Juli 2017 dengan jumlah populasi 16 remaja putri teknik sampling yang dipilih adalah tottal sampling dengan jumlah sampel yang diperoleh adalah 16 orang, data diambil menggunakan kuesioner DASS (Depression Anxiety Stress Scale) Dalam melakukan analisa data peneliti mengunakan uji chi-square $(\alpha=0,05)$.

\section{HASIL PENELITIAN}

\section{Data Umum}

Tabel 1 Distribusi Responden Berdasarkan Usia

\begin{tabular}{cccc}
\hline No & Usia & Jumlah & $\begin{array}{c}\text { Persentase } \\
(\%)\end{array}$ \\
\hline 1 & 10 & 5 & $31,25 \%$ \\
2 & $11-12$ & 9 & $56,25 \%$ \\
3 & $>13$ & 2 & $12,5 \%$ \\
\hline 4 & Total & 16 & $100 \%$ \\
\hline
\end{tabular}


Dari tabel diatas diketahui sebagian besar dari responden berusia 11-12 yang berjumlah 9 orang (56.25\%).

Tabel 2 Distribusi Responden Berdasarkan pendidikan terakhir

\begin{tabular}{|c|c|c|c|}
\hline No & Pendidikan & Jumlah & $\begin{array}{c}\text { Persentase } \\
(\%)\end{array}$ \\
\hline 1 & $\begin{array}{c}\text { Tidak } \\
\text { sekoloah }\end{array}$ & 0 & $0 \%$ \\
\hline 2 & $\mathrm{SD}$ & 16 & $100 \%$ \\
\hline 3 & SMP & 0 & $0 \%$ \\
\hline 4 & SMA & 0 & $0 \%$ \\
\hline 5 & Serjana & 0 & $0 \%$ \\
\hline 6 & Total & 16 & $100 \%$ \\
\hline
\end{tabular}

Dari tabel diatas diketahui bahwa seluruh responden berpendidikan SD yang berjumlah 16 orang (100\%).

\section{Data khusus}

Tabel 3 Distribusi Tingkat Pengetahuan responden

\begin{tabular}{cccc}
\hline No & $\begin{array}{c}\text { Tingkat } \\
\text { pengetahuan }\end{array}$ & Jumlah & $\begin{array}{c}\text { Persentase } \\
(\%)\end{array}$ \\
\hline 1 & Kurang & 10 & $62,5 \%$ \\
2 & Cukup & 6 & $37,5 \%$ \\
3 & Baik & 0 & $0 \%$ \\
\hline 4 & Total & 16 & $100 \%$ \\
\hline
\end{tabular}

Dari tabel diatas diketahui sebagian besar dari responden berpengetahuan kurang yang berjumlah 10 orang $(62,5 \%)$.

Tabel 4 Distribusi Tingkat Kecemasan responden

\begin{tabular}{cccc}
\hline No & $\begin{array}{c}\text { Tingkat } \\
\text { Kecemasan }\end{array}$ & Jumlah & $\begin{array}{c}\text { Persentase } \\
(\%)\end{array}$ \\
\hline 1 & Normal & 0 & $0 \%$ \\
2 & Ringan & 0 & $0 \%$ \\
3 & Sedang & 5 & $31,25 \%$ \\
4 & Berat & 11 & $68,75 \%$ \\
5 & Panik & 0 & $0 \%$ \\
\hline 6 & Total & 16 & $100 \%$ \\
\hline
\end{tabular}

Dari tabel diatas diketahui sebagian besar responden memiliki kecemasan berat yang berjumlah 11 orang $(68,75 \%)$.

Tabel 5 Tabulasi silang Hubungan Pengetahuan Tentang Menarche dengan Tingkat Kecemasan Remaja Putri Awal di Madrasah Ibtidaiyah Darul Ulum Tahun 2017

\begin{tabular}{|c|c|c|c|c|c|c|c|c|}
\hline & \multicolumn{5}{|c|}{ Kecemasan } & \multirow{2}{*}{$\begin{array}{c}\text { - Tot } \\
\text { al }\end{array}$} & \multirow{2}{*}{$\begin{array}{l}\text { Rank } \\
\text { spear } \\
\text { man }\end{array}$} \\
\hline & & $\begin{array}{l}\text { Nor } \\
\text { mal }\end{array}$ & $\begin{array}{l}\text { Rin } \\
\text { gan }\end{array}$ & $\begin{array}{l}\text { Sed } \\
\text { ang }\end{array}$ & $\begin{array}{c}\text { Ber } \\
\text { at }\end{array}$ & $\begin{array}{c}\text { Pan } \\
\text { ik }\end{array}$ & & \\
\hline \multirow{3}{*}{$\begin{array}{l}\text { Pen } \\
\text { get } \\
\text { ahu } \\
\text { an }\end{array}$} & $\begin{array}{l}\text { Kur } \\
\text { ang }\end{array}$ & 0 & 0 & 0 & 10 & 0 & 10 & \\
\hline & $\begin{array}{l}\mathrm{Cu} \\
\text { kup }\end{array}$ & 0 & 0 & 5 & 1 & 0 & 6 & 0,009 \\
\hline & $\begin{array}{l}\text { Bai } \\
\text { k }\end{array}$ & 0 & 0 & 0 & 0 & 0 & 0 & \\
\hline & otal & 0 & 0 & 5 & 11 & 0 & 16 & \\
\hline
\end{tabular}

Berdasarkan tabel 5 di atas didapatkan bahwa sebagian besar responden yang memiliki pengetahuan dalam kategori kurang dan memiliki tingkat kecemasan berat yaitu sebanyak 10 orang $(62,5 \%)$.

\section{PEMBAHASAN}

\section{Tingkat Pengetahuan Remaja Putri Awal Tentang Menarche}

Hasil yang telah didapatkan dari 16 responden di madrasah ibtidaiyah darul ulum pada tanggal 17 juni 2017 yang menggunakan kuesioner tentang tingkat pengetahuan tentang menarche didapatkan hasil bahwa $10(62,4 \%)$ responden berpengetahuan kurang.

Peneliti berpendapat bahwa tingkat pengetahuan remaja tentang menarche dipengaruhi oleh faktor usia dan tingkat pendidikan semakin dewasa seseorang diharapkan dapat semakin 
matang dan pengetahuan mengenai menarche juga dapat bertambah, mengenai tindakan apa yang harus dilakukan untuk mengatasi masalah yang dialami. Semakin tinggi pendidikan maka pengetahuan seseorang akan bertambah juga karena dalam pendidikan seseorang akan mendapat informasi mengenai suatu hal yang nantinya juga dapat digunakan dalam mengatasi masalahnya.

Pengetahuan bisa diperoleh melalui berbagai media misalnya saja media massa yang nantinya dapat dijadikan untuk menambah wawasan individu tersebut. (Anzwar, 2003, didalam Indriastuti, 2009, 7). Perilaku juga dipenngaruhi oleh pengetahuan sedangkan pengetahuan seseorang akan semakin tinggi sesuai dengan tingkat pendidikan yang dimilikinya (Notoatmodjo, 2003, 35).

\subsubsection{Tingkat Kecemasan Remaja Putri Awal Tentang Menarche}

Berdasarkan penelitian yang dilakukan pada 16 responden di Madrasah Ibtidaiyah Darul Ulum pada tanggal 17 Juni 2017 yang menggunakan kuisioner tentang tingkat kecemasan remaja putri awal didapatkan hasil bahwa $8(50 \%)$ responden memiliki kecemasan sedang.

Peneliti berpendapat bahwa tingkat kecemasan remaja putri dapat dipengaruhi oleh beberapa faktor salah satunya adalah pengetahuan, karena pengetahuan yang nantinya akan mempengaruhi bagaimana mereka bersikap. Remaja putri biasanya merasa cemas karena perubahan-perubahan yang terjadi pada tubuh mereka baik dari segi fisik maupun psikologis. Terkadang mereka malu untuk menanyakan atau takut untuk melakukan tindakan karena ketidaktahuan mereka ketika mengalami menstruasi saat pertama kalinya.

Konseling atau bahkan penyuluhan tentang menarche dapat digunakan dalam merubah sikap remaja agar dapat menghadapi menarche tanpa kecemasan lagi. Pengetahuan yang tinggi akan mempengaruhi tingkat kecemasan mereka (Irmawati, 2013, 7).

\subsubsection{Hubungan Pengetahuan Tentang Menarche dengan Tingkat kecemasan Remaja Putri Awal di Madrasah Ibtidayah Darul Ulum.}

Berdasarkan hasil tabulasi silang antara pengetahuan dengan kecemasan reamaja putri awal di madrasah ibtidaiyah darul ulum dalam kategori berpengetahuan kurang dan memiliki kecemasan berat yaitu sebanyak 11 responden $(68,75 \%)$. Setelah dilakukan pengujian dengan uji Rank Spearman diperoleh nilai $\mathrm{p}$ sebesar 0,009 Signifikasi hubungan dengan p-value < $\alpha$ dengan tingkat kesalahan 0,05. Karena nilai $\mathrm{p}$ adalah $0,009<0,05$, maka $\mathrm{H} 0$ ditolak dan $\mathrm{H} 1$ diterima yang berarti ada hubungan Hubungan Pengetahuan Tentang Menarche Dengan Tingkat Kecemasan Remaja Putri Awal.

Tingkat pengetahuan yang kurang akan berpengaruh pada tingkat kecemasan seseorang. Mereka yang memiliki pengetahuan tinggi atau luas mengenai menarche akan mampu melakukan upaya atau tindakan dalam mengatasi masalah yang daialami sehingga rasa cemas yang dirasakan akan berkurang. Rasa cemas ditimbulkan karena seseorang tersebut tidak tahu mengenai tindakan apa yang harus dilakukan ketika mengalami sebuah masalah. 
Pendidikan adalah bimbingan yang diberikan kepada orang lain agar dapat memahami suatu hal. Tidak dapat dipungkiri bahwa semakin tinggi pedidikan maka akan berbanding lurus dengan bagaimana orang tersebut menangkap informasi yang diterima jika semakin banyak informasi maka akan semakin banyak pula pengetahuan yang dimilikinya dan nantinya akan merubah perilaku mereka dalam mengatasi berbagai masalah yang dialaminya (Mubarak, 2007, 45).

\section{KESIMPULAN DAN SARAN}

\section{Kesimpulan}

1. Pengetahuan tentang menarche pada remaja putri awal di madrasah ibtidaiyah darul ulum sebagian besar kurang dan berjumlah 10 orang $(62,5 \%)$.

2. Tingkat Kecemasan remaja puti awal di madrasah ibtidaiyah darul ulum setengah dari respoen adalah berat dan berjumlah 11 orang $(68,75 \%)$.

3. Ada Hubungan Pengetahuan tentang menarche dengan tingkat kecemasan remaja putri awal di madrasah ibtidaiyah darul ulum. Karena terbukti bahwa remaja putri yang memiliki pengetahuan kurang dan kecemasan berat ada 5 orang.

\section{Saran}

Berdasarkan kesimpulan hasil penelitian, maka peneliti mengajukan beberapa saran yang ditujukan kepada:

1. Diharapkan tenaga kesehatan selalu memberiakan penyuluhan - penyuluhan kepada sekolah-sekolah dasar untuk meningkatkan pengetahuan anak.

2. Perlunya peran aktif tenaga kesehatan untuk meningkatlkan penyuluhan terhadap remaja putri awal tentang menarche agar tidak terlalu cemas.

3. Melakukan penelitian tentang faktor-faktor yang mempengaruhi pengetahuan seperti kurangnya memanfaatkan sarana informasi seperti sosial media, kurangya membaca koran, dan lain-lain.

\section{DAFTAR PUSTAKA}

Irmawati, Lenny. 2013. Hubungan Pengetahuan Tentang Menarche Dengan Tigkat Kecemasan Pada Remaja Putri SMPN 6 Tambun Selatan. Sekolah Tinggi Ilmu Kesehatan Medistra Indonesia. Bekasi.

Notoatmodjo, S., 2003. Pendidikan dan Perilaku Kesehatan. Jakarta: Rineka Cipta, 16, pp.15-49.

Mubarak. 2007. Promosi Kesehatan. Graha Ilmu. Yogyakarta

Yunika, Regina Pricilia. 2013. Hubungan Antara Pengetahuan Remaja Putri Dengan Perilaku Menjaga Kebersihan Alat Genetalia Pada Masa Pra Menarche Di Sd Negeri 2 Ungaran Barat. STIKES Ngudi Waluyo Ungaran. Yogyakarta. 